\title{
Evolution of Reproductive Sciences at KUMC
}

\author{
Paul Terranova
}

Vice Chancellor for Research, University of Kansas Medical Center

ermit E. Krantz, MD, was appointed chair of the department of Obstetrics \&
Gynecology at the University of Kansas Medical Center (KUMC) in 1959. His
appointment as chair was central to the establishment of reproductive research at KUMC. Dr. Krantz was a well-known physician and researcher who had trained at Northwestern University in Chicago. He had a solid reputation as an emerging physician-scientist. His goal was to establish a clinical department with an emphasis on research. Two years after his arrival at KUMC, Dr. Krantz hired Gilbert S. Greenwald, Ph.D. as the first endowed chair in human reproductive research. Dr. Greenwald had trained at the University of California at Berkeley where he received his doctorate and was introduced to the female reproductive system, which served as the foundation for the remainder of his scientific career. Dr. Greenwald trained as a postdoctoral student at the Carnegie Institute of Embryology of Johns Hopkins University with a focus on the reproductive system.

After completing his postdoctoral studies at Hopkins in 1956, he moved to Seattle where he assumed the position of Instructor of Anatomy at the University of Washington. At the University of Washington, Dr. Greenwald published his first of many monumental papers on the ovary. In 1960, at a scientific meeting, Greenwald met Krantz, the new chair of Obstetrics and Gynecology at KUMC. Dr. Krantz recognized Gil's talents and enthusiasm for research and in 1961 offered him an Endowed Professorship in Research in Human Reproduction as well as a promotion to Associate Professor. The appointment of Dr. Krantz, who subsequently appointed Dr. Greenwald as a basic research scientist in the Department of Obstetrics \& Gynecology, was the origin of a long history of outstanding reproductive research at KUMC. More faculty appointments in Obstetrics \& Gynecology occurred. Zeev Dickmann, Ph.D., who had trained at Cambridge University and later at Vanderbilt University, was recruited to KUMC in 1962. His area of research was regulation of early pregnancy and embryo implantation. Almost simultaneously, Donald C. Johnson, Ph.D., a reproductive researcher with interest in ovarian function and pregnancy, was recruited to KUMC from the University of Iowa. These three individuals served as the core from which more than 45 years of reproductive research emanates from KUMC. The primary reasons for the persistence of reproductive research were their ability to garner NIH funding 
for the research programs and the high quality of their publications. A few years later, Dr. Greenwald secured a Ford Foundation training grant in reproductive research which provided more than seven hundred thousand dollars over 15 consecutive years. This training grant supported numerous postdoctoral fellows from across the world and thus, enhanced the reputation of reproductive research at KUMC.

The Foundation provided by NIH and the Ralph L. Smith Foundation. In the mid 1960's KU obtained a program project grant entitled "Learning Disorders, Special Education and Speech Perception" from the National Institute of Child Health and Human Development (NICHD) of the NIH with leveraged monetary support from the Ralph L. Smith Foundation. There were three reproductive themes in the program project. A unique underlying principle was that abnormal reproductive processes might lead to abnormal development; at the time, little was known about these areas. Three reproductive themes in the program project grant from NIH were:

- Hormonal Regulation of Ovarian Function/ Reproductive Physiology and Neuroendocrinology led by Gilbert S. Greenwald.

- Control and Functional Relationships of Gonadotrophins led by Donald C. Johnson.

- Control of Preimplantation in Pregnancy led by Zeev Dickmann.

This program project grant was renewed as a NIH P30 grant that supported the Center in Mental Retardation and now is the Kansas Intellectual and Developmental Disabilities Research Center (www2.kumc.edu/kiddrc/). The Center is in its $43^{\text {rd }}$ year of continuous funding and represents the longest continually held NIH grant by the University. The Ralph L. Smith Foundation provided resources to assist in the building of Smith East and West as well as the Miller Building on the KUMC campus in the late 1960's.

In 1975, KU obtained a NICHD T32 postdoctoral training grant in mental retardation. Several postdoctoral fellows in reproductive biology were supported by that grant including the author of this chapter (Paul Terranova, Ph.D., Vice Chancellor for Research at KUMC). From the early 1960's through the mid 1970's, reproductive research at KUMC gained a very solid reputation both nationally and internationally even though the reproductive group had only three faculty.

The next important event in the history of reproductive research at KUMC was the appointment of Gilbert Greenwald as Chairman of the Department of Physiology in 1977. He had negotiated with the Dean to recruit several new faculty. The recruits are listed below with a short description of their reproductive research at KUMC.

Gilbert Greenwald Recruits in the Department of Physiology related to Reproductive Research:

1.James Voogt, Ph.D. was recruited in 1977. His research focused on regulation of prolactin secretion. Dr. Voogt succeeded Dr. Greenwald after his retirement as Chair of Physiology in the mid 1990's. 
2. Paul Terranova, Ph.D. was also recruited in 1977. His research focused on regulation of ovarian function. Dr. Terranova was the founding Director of the Center for Reproductive Sciences in 1995.

3. Michael Soares, Ph.D. was recruited in 1984. His research focused on placental trophoblast differentiation. Dr. Soares is the founding Director of the Institute of Maternal Fetal Biology at KUMC.

4. Joseph Tash, Ph.D. was recruited in 1990. His research focused on regulation of sperm motility and male reproductive function. Dr. Tash is the founding Director of the Center for Interdisciplinary Male Contraceptive Research \& Drug Development, a NICHD sponsored center at KUMC.

5. Peter Smith, Ph.D. was recruited in 1986. His research focused on neurobiology of the autonomic nervous system but more recently has focused on factors regulating female pelvic pain. $\mathrm{He}$ is the Director of the Kansas Intellectual and Developmental Disabilities Research Center (formerly known as the Mental Retardation Research Center), a NICHD sponsored center for 43 years on the KUMC campus.

Because of the growing success of the reproductive group within the Departments of Obstetrics \& Gynecology and Physiology, several other key recruits in various departments occurred. Those are listed below.

1.S.K.Dey, Ph.D., trained as a Ford Foundation postdoctoral fellow at KUMC in the laboratory of Zeev Dickmann, Ph.D. Dr. Dey developed his own research program in the Department of Obstetrics \& Gynecology and rose to the rank of Professor in the Department of Obstetrics \& Gynecology. His research focused on regulation of implantation during early pregnancy. He was a core and project leader in the KUMC Reproductive Center grants from NICHD. Dr. Dey subsequently moved to Vanderbilt University and then to Children's Hospital associated with the University of Cincinnati. Dr. Dey obtained two MERIT awards from NIH (NICHD and NIDA).

2.Joan Hunt, Ph.D., trained as a postdoctoral fellow at KUMC and joined the Department of Anatomy \& Cell Biology, where she is a University Distinguished Professor. She studies the immunology of early pregnancy establishment and has held numerous NIH grants, including a program project. She was a core and project leader in the KUMC Reproductive Center grants from NICHD and Associate Director of the Reproductive Center.

3. William Kinsey, Ph.D., was recruited to KUMC from the University of Miami. He is currently a Professor of Anatomy \& Cell Biology and CoDirector of the Center for Reproductive Sciences. He is also a core leader in the NICHD supported Interdisciplinary Center for Male Contraceptive Research and Drug Development at KUMC.

4. George Enders, Ph.D., Associate Professor of Anatomy \& Cell Biology, trained at Harvard University and was a core leader in the Reproductive Center grants from NICHD. His research focused on testicular development.

5. Glen Andrews, Ph.D., is a University Distinguished Professor in the Department of Biochemistry \& Molecular Biology. His research focuses on gene regulation in early development. He was recruited from Baylor College of Medicine and is an active participant in the activities of the Reproductive Center and Institute of Maternal Fetal Biology.

6. Leslie Heckert, Ph.D., is the Marion M. Osborne Professor of Molecular \& Integrative Physiology and currently Co-Director of the Center for Reproductive Sciences. She was 
also a project leader in the Reproductive Center grant and is currently a project leader in the NICHD supported Interdisciplinary Center for Male Contraceptive Research and Drug Development. She was recruited from Case Western Reserve University. Her research focuses on transcriptional regulation of testicular development.

7.Gustavo Blanco, MD., Ph.D., was recruited from Saint Louis University, is an Associate Professor of Molecular \& Integrative Physiology and a Project Leader in the NICHD supported Interdisciplinary Center for Male Contraceptive Research and Drug Development.

8. Michael Wolfe, Ph.D., was recruited from Case Western Reserve University and is an Associate Professor of Molecular \& Integrative Physiology. He was a new program development awardee in the original Reproductive Center grant from NICHD.

9.T. Raj Kumar, Ph.D., was recruited from Baylor College of Medicine and is currently an Associate Professor of Molecular \& Integrative Physiology. His research focus is on genetic regulation of reproductive development.

10. Lane Christenson, Ph.D., was recruited from the University of Pennsylvania and is currently an Assistant Professor of Molecular \& Integrative Physiology at KUMC. His research focuses on factors regulating ovarian function.

11. Katherine Roby, Ph.D., trained at KUMC and is a Research Associate Professor of Anatomy \& Cell Biology. She was an Associate core leader in the Reproductive Center grants. Her research focused on factors regulating ovarian function and ovarian cancer.

12. Daudi Langat, Ph.D., is a Research Assistant Professor of Anatomy \& Cell Biology. His research focuses on the immunology of placental development.
13. Margaret Petroff, Ph.D., is an Assistant Professor of Anatomy \& Cell Biology. She studies the immunology of implantation and early placental development. She is project leader in the program project related to immunobiology of pregnancy.

14. Warren Nothnick, Ph.D., is an Associate Professor of Obstetrics \& Gynecology. He studies the role of matrix metalloproteinases in female reproductive function with emphasis on the ovary and uterus.

15. Ajay Nangia, MD., is an Associate Professor of Urology and studies factors regulating fertility and infertility in men. He is an active participant in the NICHD supported Interdisciplinary Center for Male Contraceptive Research and Drug Development.

16. Carl Weiner, MD, is the Kermit E. Krantz Professor and Chair of the Department of Obstetrics \& Gynecology. He studies factors regulating interactions between the mother and baby using human and animal models.

17. David Albertini, Ph.D., Hall Professor in the Department of Molecular and Integrative Physiology. He studies ovarian function with emphasis on the egg.

18. Yafeng Dong, MD, Ph.D., Research Assistant Professor of Obstetrics \& Gynecology, studies maternal fetal interactions with emphasis on factors that are detrimental to the baby and mother.

19. Jeffrey Holzbeirlein, MD, Associate Professor of Urology, studies prostate cancer.

20. Sam Kim, MD., Associate Professor of Obstetrics \& Gynecology, studies factors regulating the development of egg and preservation of ovaries for patients with cancer.

21. Benyi Li, MD, Ph.D., Associate Professor of Urology studies prostate cancer.

22. Linda Nelson, MD., Ph.D., Associate Professor of Obstetrics \& Gynecology studies factors 
regulating ovarian function with emphasis on fertility and infertility.

23. Brian Petroff, DVM, Ph.D., Associate Professor of Medicine, studies ovarian aging, ovarian toxicology, and breast and ovarian cancer.

24. Gregory Vanden Heuvel, Ph.D., Associate Professor of Anatomy \& Cell Biology, studies molecular aspects of growth regulation in the kidney.

25. Xuan Zhang, MD, Ph.D., Research Assistant Professor of Obstetrics \& Gynecology, studies ovarian and uterine function.

The Center for Reproductive Sciences (Founding Director, Paul Terranova, Ph.D., 1995; www2.kumc.edu/crs/)

In 1993, the reproductive group of 10 faculty met to determine their mission and future needs of their research programs. The Center's mission is to carry out basic and clinical research in the reproductive sciences. In order to support this mission, the group discussed several grant opportunities through the NICHD, including a core based center grant, postdoctoral training grant, and program project grant. Initially, a P30 (Core-based) Center grant with a new program development component and a training grant application were submitted to NICHD after discussions with the Dean of the School of Medicine, Daniel Hollander, MD and NICHD staff. An agreement was reached with the Dean that a Center for Reproductive Sciences would be established if the NICHD center grant opportunity would be funded. Support would be promised to the Center from the School of Medicine. In addition, the KUMC Research Institute, Inc. provided support for development of the center grant application, including visits from the external advisory board that was critical for enhancing the chances of the Center's success. The grant applications (center and training) were prepared in 1995 and subsequently funded in 1996. Thus, the KUMC Center for Reproductive Sciences opened for business in 1996, thirty-seven years after the arrival of Kermit Krantz, MD, chair of Obstetrics \& Gynecology. The reasons for success in obtaining a 5-year NICHD center grant that totaled more than $\$ 1$ million were multifold. First, even though the original members, Greenwald, Johnson and Dickmann, were at the end of their careers, the junior members that Krantz, Greenwald, and others recruited in the interim (197795) had rising academic careers. Each became well established in the reproductive field. Most importantly, each member held at least one NIH grant (10 funded faculty, 16 R01s, and most of them were from NICHD) with exception of the very junior faculty. The junior, mid-level, and senior mix of the faculty in reproductive sciences was also a strength that helped garner funding support for the new program development component of the P30 application. A second reason for success was the "centeredness" that the group exhibited prior to submission of the grant. This was evidenced by regular reproductive group seminars, external review board involvement in the center, joint publications, joint grants and joint students amongst the members, and the need for sharing of resources (cores such as cell culture, DNA sequencing, transgenic/gene targeting and image analysis). The third reason for success was the support provided to the Center from the School of Medicine. 
Two years prior to competitive renewal of the Center grant, NICHD decided to end the P30-core based center program and replace it with a U54 Center mechanism that was a cooperative research agreement program. Significant changes in structure that focused on new research projects and fewer cores were required. Cooperative research with other NICHD-supported centers was also required. Thus, 4 research projects (similar to R01s) and 3 open cores (administration, cell culture and image analysis) were designed and integrated. The renewal was submitted and funded for another 5 years.

During the second 5 years, NICHD required a more focused application on a single topic with a substantial clinical component/project that integrated into the basic projects and thus, our next renewal would have to change again. This became very difficult for the large basic group at KUMC and thus, other avenues of Center grants were pursued. Most importantly, and in our favor, was that the group had grown to nearly 30 members so that initiatives could be developed for: a) male fertility regulation and infertility, b) female fertility/infertility and c) pregnancy. The pregnancy component led by Joan Hunt, Ph.D., is supported by a NICHD program project that studies the immunology of early pregnancy establishment. That project involves important collaborations with the University of Chicago as well as other universities throughout the world and is in its second 5-year renewal. The male component, led by Joseph Tash, Ph.D., is now funded as a NICHD supported
Interdisciplinary Center for Male Contraceptive Research and Drug Development with research projects and cores. The third component, female, is under development in the area of female fertility/infertility.

The NICHD supported Interdisciplinary Center for Male Contraceptive Research and Drug Development (Founding Director, Joseph Tash, Ph.D., 2007; www.kumc.edu/mc/)

This Center is supported largely by a Cooperative Agreement grant from the Contraceptive Research Branch of NICHD. Three research projects led by Joseph Tash, Gustavo Blanco and Leslie Heckert are the center piece of the grant. The grant focuses on developing novel non-steroidal drugs that block sperm development and assess their mechanism of action. The group collaborates with researchers at the University of California at San Francisco, University of Minnesota, HauptmanWoodward Medical Research Institute, UMDNJ-RW Johnson Medical School, Vivo Quest, University of Pennsylvania, and Wyeth. In addition, the Center has 3 NICHD supported cores, administration, drug design/synthesis/discovery led by Gunda Georg, Ph.D., at the University of Minnesota and former KU Faculty member, and an imaging core. A \$2.8 million NICHD subcontract through the University of Minnesota (Dr. Georg as PI) to test and further develop male contraceptives is also an important component of this Center. This group is heavily involved in drug discovery and development and thus interacts closely with the Institute for Advanced Medical Innovation. Dr. Heckert, a member of 
this Center, is also developing another Center grant application focused on male infertility. Dr. Tash has expanded the concept of fertility regulation to pet species (cats and dogs) and is vying for a grant from the Michelson Foundation to further develop this idea.

Institute for Maternal Fetal Biology (Founding Director, Michael Soares, Ph.D., 2002; www.imfb.org)

The mission of the Institute for Maternal Fetal Biology is to improve the health and quality of life for mothers and babies. Currently, there are 13 faculty in the Institute from KU, including Lawrence, Kansas City and one from Children's Mercy Hospital (Kansas City, Missouri) with a NIH grant portfolio of $\sim \$ 4$ million annually. The faculty in the Institute study diseases of pregnancy such as: preeclampsia, early pregnancy loss, intrauterine growth restriction; diseases of the fetus including anemia, thalassemia, sexual development, maternal substance abuse, birth defects, and pulmonary development and lung injury.

\section{Summary}

The current reproductive research at KUMC emanated from the Department of Obstetrics in 1959 when Kermit Krantz, MD was appointed chairman of the department. Dr. Krantz hired Gilbert Greenwald, Ph.D. who became a world class leader in reproductive biology and led KUMC faculty recruiting to the utmost. His involvement in the longest standing (43 years) NIH supported Center (Kansas Intellectual and Developmental Disabilities Research Center) led to the formation of the Center for Reproductive Sciences, Interdisciplinary Center for Male Contraceptive Research and Drug Development, and the Institute for Maternal Fetal Biology. 